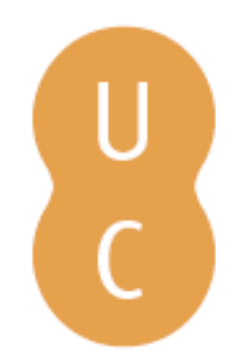

\title{
nombalina
}

\section{Uma pedra no sapato antigo: sobre Moralia de Plutarco e Vespas de Aristófanes}

Autor(es): $\quad$ Silva, Francisco Alison Ramos da

Publicado por: Imprensa da Universidade de Coimbra

URL

persistente:

URI:http://hdl.handle.net/10316.2/38232

DOI:

DOI:http://dx.doi.org/10.14195/978-989-26-1053-5_13

Accessed : $\quad$ 26-Apr-2023 11:48:44

A navegação consulta e descarregamento dos títulos inseridos nas Bibliotecas Digitais UC Digitalis, UC Pombalina e UC Impactum, pressupõem a aceitação plena e sem reservas dos Termos e Condições de Uso destas Bibliotecas Digitais, disponíveis em https://digitalis.uc.pt/pt-pt/termos.

Conforme exposto nos referidos Termos e Condições de Uso, o descarregamento de títulos de acesso restrito requer uma licença válida de autorização devendo o utilizador aceder ao(s) documento(s) a partir de um endereço de IP da instituição detentora da supramencionada licença.

Ao utilizador é apenas permitido o descarregamento para uso pessoal, pelo que o emprego do(s) título(s) descarregado(s) para outro fim, designadamente comercial, carece de autorização do respetivo autor ou editor da obra.

Na medida em que todas as obras da UC Digitalis se encontram protegidas pelo Código do Direito de Autor e Direitos Conexos e demais legislação aplicável, toda a cópia, parcial ou total, deste documento, nos casos em que é legalmente admitida, deverá conter ou fazer-se acompanhar por este aviso.

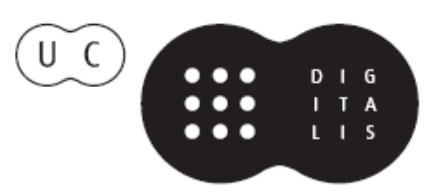




\section{Grécia e Roma no universo de Augusto}

\section{Ana Maria César Pompeu Francisco Edi de Oliveira Sousa (Orgs.)}

IMPRENSA DA UNIVERSIDADE DE COIMBRA

ANNABLUME 


\title{
UMA PEDRA NO SAPATO ANTIGO: sobre Moralia de Plutarco e Vespas de Aristófanes (A Stone in the Old Shoe: on Plutarch's Moralia, and Aristophanes' Wasps)
}

\author{
Francisco Alison Ramos da Silva 292 (alison84-ramos@hotmail.com) \\ Universidade Federal do Ceará
}

\begin{abstract}
Resumo - Não nos surpreende a escassa generosidade da maioria das críticas filosóficas desenvolvidas na Antiguidade Clássica sobre a comédia. Noções como imitação e ética não comungam em muitos aspectos com o gênero cômico nos pensamentos de Platão e Aristóteles. Mas que dizer de críticas que visam a uma análise comparativa dos períodos da comédia grega, como as de Plutarco? Nesse caso, faz-se necessária a consideração de algumas questões, como as diferentes situações políticas da produção da Comédia Antiga e dos Moralia de Plutarco, em que o autor afirma que as peças de Aristófanes não são dignas de admiração, uma vez que despertam náusea. $O$ que poderia justificar tal julgamento? A leitura atenta das comédias de Aristófanes, mormente a de Vespas, é de grande utilidade para demonstrar que, por uma questão política, Plutarco pode ser uma "pedra" nos "sapatos antigos" da comédia grega.

Palavras-chave - comédia, Aristófanes, Vespas, Plutarco, Moralia.
\end{abstract}

Aвstract - The scarce generosity of most ancient philosophical criticism on comedy is unsurprising. Notions such as imitation and ethics do not go together in many regards with the comic genre in the thoughts of Plato and Aristotle. However, what about the criticism aimed at a comparison of the periods of Greek comedy, such as Plutarch's? In this case, it is necessary to consider certain issues such as the different political situation of production of the Old Comedy and Plutarch's Moralia, in which the author states that the Aristophanes' plays are not worthy of admiration because they are allegedly nauseating to their readership. What similarities between the periods of production of the Greek New Comedy and Plutarch's century could justify such judgment? A careful reading of the Aristophanes' comedies, especially the Wasps, is of great use to demonstrate that, as a political issue, Plutarch can be a "stone" in the old shoes of Greek comedy.

KeYwords - comedy, Aristophanes, Wasps, Plutarch, Moralia.

No corpus dos Moralia (853a ss.), de Plutarco, há um breve resumo de uma obra perdida cujo título é Compêndio da Comparação entre Aristófanes e Menandro. Pela própria designação do título, já sabemos tratar-se de uma obra de crítica literária que, como a maioria das críticas, privilegia determinados textos em

${ }^{292}$ Alison Ramos holds a degree in Language (2011) and a Master's degree in Comparative Literature from the Federal University of Ceará; he is currently engaged in a doctoral research on Aristophanes' comedy at the same University. 
detrimento de outros. Assim, alguns equívocos podem ser vistos de imediato e devem ser, portanto, orientados com maior lucidez, uma vez que a tradição que os sustenta mostrou-se hostil à Comédia Antiga, conforme expresso por Atkins (1934: 319-21). Em seu tratado, Plutarco (Silva 2013: 112-113) escreve:

A grosseria, o vulgar e o mau gosto na linguagem como há em Aristófanes, de maneira nenhuma existe em Menandro. Pois, o espectador inculto e estúpido é convencido pelo que diz aquele, mas o espectador culto suportará de má vontade. Refiro-me às antíteses, às palavras de desinência semelhante e às paronímias. Pois um se utiliza de tais recursos de modo conveniente e raro, se ocupando destes com cuidado, mas o outro se utiliza frequentemente e de modo não oportuno e frio (...).

Além do mais, na construção de seus discursos, está presente o trágico, o cômico, o pomposo, o vulgar, a obscuridade, a linguagem de uso comum, a faustuosidade e a elevação..., a charlatanice e a frivolidade nauseante. E, com tantas diferenças e discordâncias, seu estilo não transmite o conveniente e o natural a cada personagem, me refiro, por exemplo, a majestade para um rei, a eloquência para um orador, a simplicidade para uma mulher, o prosaico para um ignorante, a vulgaridade para um homem comum; mas atribui aos personagens, como se a partir de um sorteio, as expressões que encontra ao acaso, e não poderias julgar se o que fala é um filho ou um pai, se é um homem rústico ou um deus, uma anciã ou um herói.

Essas são palavras que careceriam de uma consideração da totalidade da obra de Aristófanes. Afinal, parece que o maior representante da Comédia Ática organizou a feitura de seu trabalho de modo que suas comédias parecessem uma unidade. Este ensaio, no entanto, não pode tratar de todo o assunto de Aristófanes. Por isso, o assunto mais urgente são as atribuições "mal feitas" pelo comediógrafo - segundo Plutarco - quanto à inversão dos papéis de pai e filho e, em seguida, quanto à qualidade "frívola" e "nauseante" dos textos aristofânicos. Para tal segmento, não há exemplo mais oportuno do que Vespas, cujas personagens mais importantes são o velho juiz Filocléon (o que ama Cléon) e seu filho Bdelicléon (o que odeia Cléon).

O prólogo da peça começa com um diálogo entre os escravos Sósia e Xântias, a quem Bdelicléon atribuiu a guarda do pai para que o velho não saísse de casa. Depois do vinho, da perseguição do sono e dos sonhos que os escravos contam um para o outro, Xântias anuncia ao público o assunto da peça, afirmando que dessa vez as cenas não vão tratar de coisas "baixas" nem elevadas, mas de um assunto engenhoso. $\mathrm{O}$ interesse do filho em prender o pai dentro de casa se deve ao fato de o velho ter desenvolvido uma mania por julgamentos. Bdelicléon tenta fazer de tudo para curar o pai, chegando até mesmo a levá-lo em vão ao templo do deus Asclépio. A única saída que encontra é recorrer aos escravos, que vigiam continuamente Filocléon, e colocar redes em volta da casa para evitar qualquer tentativa de fuga. 
Os outros juízes, e igualmente velhos, estão prestes a passar pela casa de Filocléon para que juntos possam ir ao tribunal. O filho tenta convencer com discursos o pai, a quem vê como escravo daquele sistema político e não como cidadão livre. A doença do velho é, na verdade, a doença da cidade e os velhos que formam o coro da peça são como vespas, cujos ferrões ferem os seus próprios concidadãos, na ostentação de uma fraqueza democrática que tem pretensão de ser um exercício político eficaz. Essas vespas são frutos de um engano doentio, que se sustenta numa terrível ignorância. Quando o coro se dá por vencido depois do agón (disputa) discursivo com Bdelicléon, aconselha o pai a escutar o filho. O velho aceita, mas com uma condição: que não seja proibido de julgar. Então, o jovem transforma a própria casa num tribunal, onde o velho julgará problemas domésticos.

O primeiro caso a ser sugerido é o de Labes, o cão que havia roubado da cozinha um queijo da Sicília. Depois de invocar Apolo, Bdelicléon faz com que o pai se engane ao depositar o voto numa urna errada, absolvendo o cão, ao invés de condená-lo. A partir desse momento sucedem muitas coisas: o velho desmaia e logo em seguida sai da cena com o filho, para que se dê a "Parábase", momento em que é feita uma espécie de elogio da peça que, por ironia, termina com as marcas farsescas que Xântias identificou no "Prólogo" como coisas baixas e que, portanto, não seriam representadas naquele concurso. Filocléon dança, acompanhado por três dançarinos filhos de Carcino, poeta trágico a quem Aristófanes não raro satirizava.

O propósito maior de Vespas é a justiça, conforme se esclarece nesta passagem (v. 443-449):

CORO - Porventura não está a velhice sujeita a muitos e terríveis males? É evidente. Estes dois mantêm preso pela força seu velho amo, esquecendo-se das peles de cabra e das túnicas que ele lhes comprava, dos bonés de pele de cão, do cuidado que tinha no inverno em preservar-lhes os pés dos rigores do frio. Eles, porém, não têm respeito algum, nem mesmo no olhar, pelos antigos... sapatos! ${ }^{293}$

Nesse momento, o velho já tinha sido preso em casa pelo filho e pelo escravo. A crítica do Coro contra o jovem surge como um recurso retórico para reforçar a ironia de Aristófanes contra o andamento da justiça na Atenas de seu tempo. A ordem antiga, atual por ocasião da encenação da peça, orgulhava-se de promover segurança e justiça para o povo, quando os próprios juízes não apenas eram cruéis, mas também se viam obrigados a sê-los para o sustento básico de suas famílias - fruto de um sistema cruel em vigor. Assim, o exercício da democracia

${ }^{293}$ Tradução de Junito de Souza Brandão (Aristófanes 1986). 
reclama o abandono das "peles de cabra" e dos "bonés de pele de cão" que, ao ostentarem cuidado, proteção e aquecimento contra o frio, precipitam um inverno mais violento, feito por juízes que são como vespas. Assim, os sapatos antigos devem ser substituídos por novos caminhos políticos. A exigência do novo se faz por todos os meios aos quais a comédia tem acesso. Essa inversão dos papéis de pai e filho acontece também em Nuvens, sugerindo, ao modo de Vespas, a troca de uma ordem velha por uma nova.

As peças de Aristófanes mantêm íntima relação com a estrutura dos mimos (farsas), conforme se nota nas brincadeiras de Filocléon. Isso justifica a liberdade da linguagem e da performance, pelas quais se revelam as coisas "baixas", rejeitadas pela pedagogia de Plutarco. O que não se justifica, no entanto, é a rejeição de Aristófanes como autor de uma poesia que não é apenas prazerosa, mas também educativa. Ainda que para isso os meios de que se utiliza sejam considerados "grotescos", já que o que vale é o "lugar" aonde se quer chegar com esses esclarecimentos: o sublime, cujo caminho de alcance considero tratar-se de uma séria orientação ética.

Fernández (1996: 14) concorda com a força política do gênero cômico ao escrever que

[...] a comédia adota uma atitude crítica e... desintegrante da realidade político-social contemporânea. Se a tragédia dirige seu olhar para o passado, no que tem de grandioso e sobre humano, a comédia o põe na atualidade imediata para avaliar seus defeitos e suas misérias e expô-los à opinião pública... A faculdade do "tudo dizer", à parrhesía do cômico, se estimava uma manifestação da igualdade ante a lei (isonomia) dos cidadãos e as intenções de adverti-los. ${ }^{294}$

De fato, a comédia desconstrói a realidade política e social em que atua. Nesse sentido, percebemos o caráter móvel em que se configura o teatro de Aristófanes. Se, por um lado, a intenção de suas comédias não é gerar uma reflexão profunda acerca da tradição religiosa de seu povo, já que sua intenção poética é mais modesta, por outro, é essa mesma modéstia que pretende alcançar mais longe, através da crítica à atualidade: contrastar com as condições idealizadas pela reflexão dos mitos - crenças em geral - a injustiça das modalidades de vida presentes, as falhas das estruturas sociais (as desigualdades), as guerras, o abuso de poder por quem controla as leis etc. Essa maneira quase imediata de acertar

${ }^{294}$ la comedia adopta una actitud crítica y... denigratoria de la realidad político-social contemporánea. Si la tragedia dirige su mirada hacia el pasado, en lo que tiene de grandioso o sobrecogedor, la comedia lo pone en la actualidad inmediata para avizorar sus defectos y sus miserias y exponerlos a la opinión pública... La facultad del 'todo decir', la parrhesía del cómico, se estimaba una manifestación de la igualdad ante la ley (isonomia) de los ciudadanos y los intentos de coartarlos. (Tradução nossa). 
seus alvos dá à comédia aristofânica um caráter aparente de simplicidade ou de desorganização.

Quanto ao modo como Aristófanes retrata seus "heróis" (quase sempre desfigurados), cujas características populares são de extrema relevância, é interessante tomar nota destas palavras, de Fernández (1996: 20), que ainda comenta, com base em suas leituras de Reinhardt, afirmando que esse herói, além de fabuloso e sensível, é "astuto e covarde, paciente e vencedor, néscio e inteligente, louco e criativo; como um tipo que sabe sair-se a seu modo em qualquer ocasião, por mais difícil que seja”. ${ }^{295}$ Esse herói sem limites é capaz de muitas coisas e por isso mesmo sempre nos surpreende.

Isso tudo não é novidade para os leitores da Comédia Ática. Aristófanes muitas vezes se declara conselheiro, mestre e guia de seus concidadãos, conforme se pode ler em Cavaleiros, Nuvens e em famosos versos de Acarnenses (497-501), que contêm as palavras mais importantes de Diceópolis. As passagens de Vespas a esse respeito são mais uma evidência de que a comédia sabe das coisas justas e as defende. E se ela faz isso é porque o poeta assume postura legítima: a de educador político, que pode ser reconhecido como um phármakon (fármaco). Este dá o diagnóstico das doenças da cidade, oferecendo os antídotos possíveis.

Em defesa das "grosserias" de Aristófanes, que n'As Vespas aparecem já no diálogo de abertura da peça, na brincadeira dos escravos com as flatulências humanas, tomo como argumento um texto recente, esta passagem, preciosíssima, de “Miguilim”, conto de Campo Geral, de João Guimarães Rosa (1984: 52):

Miguilim tinha pegado um pensamento, quase que com suas mãos. “- Deix’ele ir, Dito. Ele vai amarrar-o-gato...” - ainda escutava dizer o vaqueiro Jé. Mentira. Tinha mentido, de propósito. Era o único jeito de sozinho poder ficar, depressa, precisava. Podiam rir, de que rissem, ele não se importava. Mesmo agora ali estava ele ali, atrás das árvores, com as calças soltadas, acocorado, fingindo. Ah, mas livre de todos; e pensava, ah, pensava! Repensava aquele pensamento, de muitas maneiras amarguras. Era um pensamento enorme, aí Miguilim tinha de rodear de todos os lados, em beira dele. $\mathrm{E}$ isso era, era! Ele tinha de morrer? Para pensar, se carecia de agarrar coragem - debaixo da exata idéia, coraçãozinho dele anoitecia.

Nessa passagem, a importância de eventos escatológicos se sobrepõe a qualquer reflexão acerca do cômico, porque o conto se desenvolve claramente por linhas trágicas. Sem pretender reduzir a grandeza desse texto, obra da maturidade artística do autor, quero apenas chamar atenção para um pequeno detalhe. Além da inocência que atravessa quase toda a narração, sobretudo o modo como

295 astuto y cobarde, paciente y vencedor, necio e inteligente, loco y inventivo; como un tipo que sabe salirse con la suya en qualquer ocasión, por muy difícil que sea. (Tradução nossa). 
Miguilim enxerga o mundo e as pessoas, e além de problemas freudianos, como a relação do menino com a mãe, o pai, o gato, o sonho e a morte, o que esse conto oferece de quase imperceptível é um tesouro para as abordagens do cômico. Uma interpretação cautelosa pode tocar as zonas baixas do corpo e o pensamento.

Miguilim prefere ter um momento só para si e para isso finge ir fazer suas necessidades no mato. Não se importa com o riso dos outros, porque seu interesse é ruminar "um pensamento enorme" que ele "tinha pegado", "quase que com suas mãos”. Nessa parte do conto, faz-se uma espécie de elogio da escatologia e do riso, relacionando-os com o exercício grandioso do pensamento. E, para pensar, Miguilim tem de fingir.

Somente uma reflexão aberta e desarmada sobre o cômico pode tender à aceitação daquilo que a comédia - generosa - abraça. Para que esse tipo de crítica tenha vida, urge que se propicie o minimamente possível à liberdade da expressão política. Ou, pelo menos, que se tenha uma boa dosagem de audácia para dizer ao máximo, ainda que as condições não sejam tão favoráveis.

Aristófanes pôde dizer, não apenas porque viveu a fase áurea da democracia ateniense, mas também e principalmente porque assim o quis. Disse o que o povo precisava ouvir, ainda que fosse assunto doloroso. A obsessão pela verossimilhança, pretendida em tempos posteriores por Plutarco, não poderia ter tido força suficiente para controlar o gênio da Comédia Antiga. Os reis de Aristófanes não são majestosos, conforme a pregação, quase religiosa, do Império em Roma; seus escravos não são tão vis quanto se lê na poética aristotélica; seus mendigos não são pobres e suas mulheres não são tão simples quanto quer a pseudo-democracia familiar. Como Miguilim, a comédia de Aristófanes se reveste de camadas de disfarces - indo ao "baixo" e ao "grotesco" - para subir de volta com "um pensamento enorme”, que porventura tenha "pegado", “quase que com as mãos”. Porque, ao contrário dos regimes ditatoriais, que experimentam a psicose do mundo perfeito, a comédia não pode ter muito pudor. E seus sapatos antigos tampouco podem conter tais pedras. 


\section{REFERÊNCIAS BIBLIOGRÁFICAS}

Aristófanes (1986), “As Vespas”, tradução de Junito de Souza Brandão, in: Eurípides; Aristófanes, O ciclope: um drama satírico. As Rãs e As Vespas: duas comédias. Rio de Janeiro.

Atkins, J. W. H. (1934), Literary Criticism in Antiquity. Vol. II (Graeco-Roman). Cambrigde.

Fernandez, L. G. (1996), Aristófanes. Madrid.

Rosa, J. G. (1984), "Miguilim”, in Rosa, J. G., Campo Geral. Rio de Janeiro.

Silva, L. L. (2013), "Lições de Plutarco Sobre a Comédia Grega”, in Pompeu, A. M. C.; Brose, Robert de; Araújo, O. L.; Oliveira, R. A. (org.), Identidade e Alteridade no Mundo Antigo. Fortaleza, 109-116. 